\title{
Antibiotic treatment impairs protein digestion in the honeybee, Apis mellifera
}

\author{
Esther E. Du Rand ${ }^{1}$, Christian Stutzer $^{2}$, Hannelie Human ${ }^{1}$, Christian W. W. PIRK ${ }^{1}$, \\ Susan W. NiCOLSON ${ }^{1}$ \\ ${ }^{1}$ Department of Zoology and Entomology, University of Pretoria, Private Bag X20, Hatfield 0028, South Africa \\ ${ }^{2}$ Department of Biochemistry, Genetics and Microbiology, University of Pretoria, Private Bag X20, Hatfield 0028, South \\ Africa
}

Received 26 April 2019 - Revised 11 October 2019 - Accepted 7 November 2019

\begin{abstract}
Nutritional stress due to habitat transformation and loss is one of several factors contributing to current declines in global bee populations. Bees obtain protein from pollen, which in honeybees is consumed and digested by nurse bees. They then distribute the protein to the rest of the colony in the form of hypopharyngeal gland secretions. Little is known of how efficiently honeybees digest protein. Moreover, antibiotics are used by beekeepers as in-hive treatments for diseases and may interfere with microbial contributions to protein digestion. Caged, newly emerged workers of Apis mellifera scutellata were fed caseinate as protein source, to investigate the effects of protein intake and antibiotic treatment on digestive efficiency. These workers were fed protein:carbohydrate ratios of $1: 120,1: 50$ and $1: 15$ or pure sucrose for 9 days. Half the cages received dietary oxytetracycline at a concentration used by beekeepers. Antibiotic exposure did not affect survival or protein consumption. Protein digestive efficiency increased with increasing levels of protein in the diet, although a decrease would have contributed to maintaining nutrient balance. Importantly, we show that antibiotic exposure impaired protein digestive efficiency, especially on low-protein diets. This may be particularly important when colonies are restricted to a single protein deficient source of pollen.
\end{abstract}

\section{Bee nutrition / Protein digestion / Digestive efficiency / Antibiotic / Oxytetracycline}

\section{INTRODUCTION}

Nutritional stress due to habitat transformation and loss is thought to be among the major factors contributing to current declines in global bee populations (Goulson et al. 2015; Vanbergen and the Insect Pollinators Initiative 2013). In honeybees, nutritional stress negatively impacts brood rearing

Electronic supplementary material The online version of this article (https://doi.org/10.1007/s13592-019-00718-4) contains supplementary material, which is available to authorized users.

Corresponding author: E. du Rand, ezette.durand@gmail.com

Manuscript editor: Cedric Alaux and development, life span, foraging capacity and resistance to diseases and pesticides (Di Pasquale et al. 2016; Scofield and Mattila 2015; Avni et al. 2014; Schmehl et al. 2014; Alaux et al. 2010).

Honeybees meet all their nutritional needs with nectar and pollen collected from a diversity of floral resources (Wright et al. 2018; Brodschneider and Crailsheim 2010). Pollen is the primary source of protein, and its main consumers are nurse bees, the young workers that digest the pollen and produce protein-rich jelly in their hypopharyngeal glands (Crailsheim and Stolberg 1989). This jelly is fed to the larvae and queen but also to nest mates through trophallactic interactions, efficiently distributing the protein and other nutrients extracted from the pollen throughout the colony (Wright 
et al. 2018; Crailsheim et al. 1992). Pollen consumption starts about 10 hours after worker emergence, steadily increasing to reach a maximum in about 8-day-old nurse bees before declining to minimal amounts in foragers (Crailsheim et al. 1992). Proteolytic activity measured in the midgut of workers follows a similar pattern: increasing shortly after emergence and reaching a maximum in around 8-day-old nurse bees (Crailsheim and Stolberg 1989). In foraging workers, sufficient proteolytic activity remains for the digestion of proteins in the jelly received through trophallaxis (Brodschneider and Crailsheim 2010; Crailsheim et al. 1992; Crailsheim and Stolberg 1989).

There are few measurements of the efficiency with which honeybees digest consumed protein (DeGrandi-Hoffman et al. 2016; Wang et al. 2014; Schmidt and Buchmann 1985). Pollen is notoriously difficult to digest (Nicolson et al. 2018), but the commercially available protein supplements provided by beekeepers to compensate for poor nutrition may be even less digestible (DeGrandiHoffman et al. 2016). Research using such supplements shows that protein source and protein intake may influence protein digestive efficiency (DeGrandi-Hoffman et al. 2016; Brodschneider and Crailsheim 2010). Diet composition is also important. When nutrient balance cannot be achieved by adjusting food selection and intake, as when insects are restricted to nutritionally imbalanced diets, they may use post-ingestive regulation mechanisms. These include modulating digestive efficiency and absorption through differential secretion of digestive enzymes, changing the gut passage rate or gut morphology, as well as adjusting metabolism and excretion after absorption (Clissold et al. 2010, 2013; Behmer 2009). For example, when the caterpillar Estigmene acrea consumes protein in excess, excretion of undigested protein increases (Telang et al. 2003), while in locusts (Locusta migratoria) uric acid excretion increases (Zanotto et al. 1993). Conversely, when dietary protein is diluted, grasshoppers (Melanoplus differentialis ) increase protein digestive efficiency by increasing gut width and length (Yang and Joern 1994).

Another factor to consider is the role of the gut microbial communities in the breakdown and absorption of nutrients. Gut microbiota possess a large repertoire of metabolic capabilities (Douglas 2009). In humans, herbivorous vertebrates and insects, there is strong evidence that gut microbes are involved in the utilisation and catabolism of essential and nonessential amino acids, provide hosts with vitamins, or aid in making nutrients more readily available to the hosts, e.g., by fermenting complex dietary carbohydrates (Davila et al. 2013). Honeybees are associated with specific gut microbiota dominated by eight to ten phylotypes (Lee et al. 2015, 2018; Kwong and Moran 2016; Moran et al. 2012). These include the proteobacteria Snodgrassella alvi (Betaproteobacteria), Parasaccharibacter apium (Alphaproteobacteria), Frischella perrara and Gilliamella apicola (Gammaproteobacteria), Lactobacillus species (Firmicutes), Bifidobacterium species (Actinobacteria) and rarer Bacteroidetes (Lee et al. 2015, 2018; Kwong and Moran 2016). Metagenomic and experimental studies suggest roles in defence against pathogens (Raymann et al. 2017; Koch and Schmid-Hempel 2011) and in digestion and neutralisation of dietary toxins (Lee et al. 2018; Zheng et al. 2016). The Gilliamella, Lactobacillus Firm-5 and Bifidobacterium clades are able to utilise plant-derived saccharides, including the complex carbohydrate pectin, and also plant-derived secondary sugars that are toxic to bees (Lee et al. 2018). Metagenomic analysis revealed that Bacilli possess a diverse repertoire of peptidase-encoding genes for protein hydrolysis, while $\gamma$-Proteobacteria and the Actinobacteria are predicted to synthesise all essential amino acids, as well as other nonessential amino acids (Lee et al. 2015).

The honeybee gut microbiome is altered in both size and composition by exposure to antibiotics (Li et al. 2019; Raymann et al. 2017). Managed colonies are routinely treated with antibiotics such as oxytetracycline to prevent and control American and European foulbrood, highly contagious bacterial diseases of honeybee larvae caused by Paenibacillus larvae and Melissococcus plutonius, respectively (Tian et al. 2012; Genersch 2010). Oxytetracycline, like most other tetracyclines, binds to the microbial 30S ribosomal subunit preventing the amino-acyl tRNA from binding to the ribosomal acceptor (A) site, thereby inhibiting polypeptide elongation (i.e., protein 
synthesis) resulting in eventual cell death (Chopra and Roberts 2001). Aside from the latter, impairment of microbial protein synthesis can influence essential functions of beneficial microbiota at the microbial-host interface, which include protein catabolism and amino acid metabolism. Consequently, it is plausible that the overuse of antibiotics could negatively affect the digestive efficiency of protein by disrupting the natural gut microbiota, contributing to nutritional stress.

A better understanding of the factors that influence protein digestive efficiency is central to developing effective means to alleviate the effects of poor nutrition in managed honeybees. In this study, we investigated the effects of protein intake and antibiotic treatment on digestive efficiency in 3- to 9-day-old worker bees, the age range responsible for digesting and distributing protein in the colony. We predicted that (1) when bees are fed high-protein diets, they will consume less than when feeding on low-protein diets and (2) that the excess protein consumed while feeding on high-protein diets will not be digested and therefore should appear in the excreta. We further predicted that (3) antibiotic treatment will interfere with protein metabolism.

\section{MATERIALS AND METHODS}

\subsection{Caged bees}

Frames with capped brood were collected during late spring and summer from six colonies of Apis mellifera scutellata Lepeletier maintained at the University of Pretoria apiary. Newly emerged workers were collected within $24 \mathrm{~h}$ of emergence, placed in clear hoarding cages ( 50 bees per cage, see Figure S1) and kept in an incubator at $34 \pm 1$ ${ }^{\circ} \mathrm{C}$ and $45 \% \mathrm{RH}$ in darkness, to simulate conditions within the hive. Feeding vials $(2 \mathrm{ml}$ Eppendorf tubes) were inserted horizontally into the cages, one with water and one with diet, provided fresh daily. Dead bees from each cage were removed and counted on a daily basis.

\subsection{Diets and feeding trials}

Caged workers were presented with no-choice liquid diets made to specific protein to carbohydrate $(\mathrm{P}: \mathrm{C})$ ratios by weight. Caseinate (sodium caseinate, Sigma-Aldrich, St Louis, MO, USA), a milk-derived protein, was used as protein. Caseinate is not part of the natural diet of honeybees, but it is commonly used in nutritional studies on a variety of animals including honeybees (Altaye et al. 2010; Archer et al. 2014a). The carbohydrate concentration remained constant (30\% sucrose (Paoli et al. 2014)). Three P:C ratios $(1: 15,1: 50,1: 120)$ were used. For each colony $(\mathrm{N}$ $=6$ colonies $)$, cages were divided into eight groups of three, each group provided with one of eight diets: 0:1 (sucrose-only), 1:15, 1:50 and 1:120 $\mathrm{P}: \mathrm{C}$, and the same diets containing $450 \mu \mathrm{g} / \mathrm{ml}$ antibiotic (18 hoarding cages in total per treatment group). Oxytetracycline (oxytetracycline hydrochloride, Sigma-Aldrich, St Louis, MO, USA), a commonly used antibiotic in apiculture, was included at a dose of $450 \mu \mathrm{g} / \mathrm{ml}$, slightly lower than used in beekeeping (Raymann et al. 2017) (The oxytetracycline powder was dissolved in the liquid diets to a final concentration of $450 \mu \mathrm{g} / \mathrm{ml}$.) After 3, 6 and 9 days, one cage per diet group was randomly selected and given a sucrose-only diet for $72 \mathrm{~h}$ to ensure that undigested protein and byproducts of protein catabolism reached the rectum (Wang et al. 2014). The trial therefore took 12 days (Figure 1A). After $72 \mathrm{~h}$, rectal contents were collected by dissection (caged honeybees do not defecate). For each diet, pooled samples from 10 bees were collected either in $400 \mu$ l double-distilled deionised water before being freeze-dried and stored at $4{ }^{\circ} \mathrm{C}$ until free amino acid analysis or in $400 \mu 140$ mM Tris buffer containing SigmaFast ${ }^{\mathrm{TM}}$ Protease inhibitor tablets (Sigma-Aldrich, St Louis, MO, USA) before being stored at $-20{ }^{\circ} \mathrm{C}$ for protein and uric acid analysis.

To determine diet consumption, diet tubes were weighed and replaced every $24 \mathrm{~h}$. We measured evaporation rates for each diet in cages without bees and adjusted consumption accordingly. Consumption (mg/bee) was adjusted for declining bee numbers in each cage during the feeding trials. Protein digestive efficiency was calculated using the formula: (protein intake - faecal protein)/protein intake $\times 100$ (Schmidt and Buchmann 1985). Samples obtained from the control diets (sucroseonly) were used to correct for endogenous protein in the rectum (Wang et al. 2014). 
a
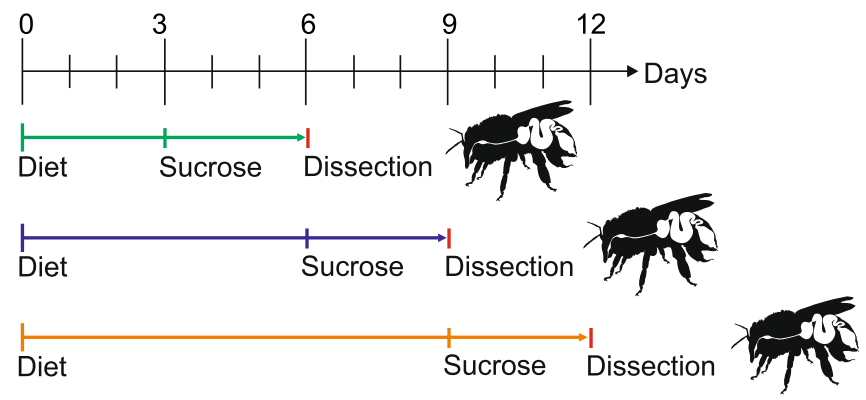

\begin{tabular}{|l|l|l|l|l|}
\hline \multicolumn{5}{|l|}{ Diets P:C ratios (caseinate:sucrose) } \\
\hline No OTC & $0: 1^{*}$ & $1: 15$ & $1: 50$ & $1: 120$ \\
\hline OTC $(450 \mu \mathrm{g} / \mathrm{ml})$ & $0: 1^{*}$ & $1: 15$ & $1: 50$ & $1: 120$ \\
\hline
\end{tabular}

${ }^{*}$ Control diet

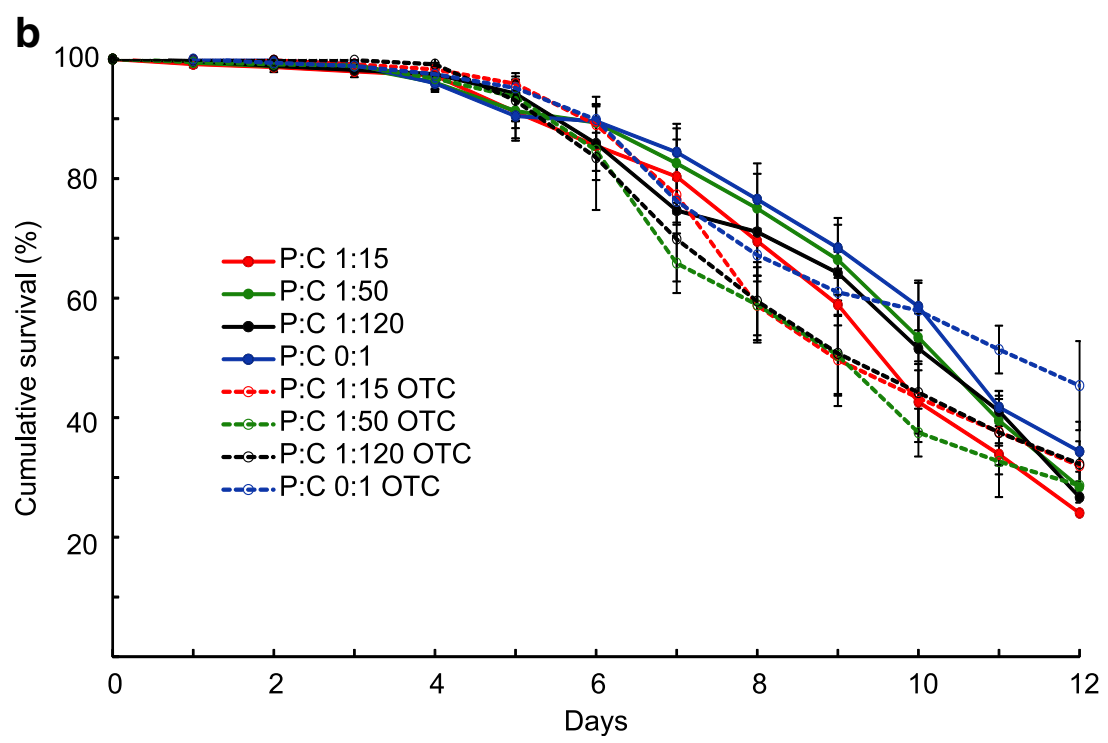

Figure 1. Experimental design and cumulative survival of bees fed varying levels of protein in the presence and absence of oxytetracycline (OTC). [A] The 12-day dietary study was conducted using caged workers presented with no-choice liquid diets made to specific protein to carbohydrate (P:C) ratios. We used weight-to-weight proportions where the carbohydrate concentration remained constant ( $30 \%$ sucrose). After 3, 6 or 9 days, the bees were placed on a sucrose-only diet for $72 \mathrm{~h}$ to ensure that all the undigested protein and by-products of catabolism reached the rectum before sampling of the rectal contents. [B] The cumulative survival plots of bees fed varying levels of dietary protein in the presence and absence of 450 $\mu \mathrm{g} / \mathrm{ml}$ oxytetracycline (OTC) for 3, 6 and 9 days. Data is presented as the mean $\pm \mathrm{SE}(\mathrm{N}=6,50$ bees per cage).

2.3. Determining protein, uric acid and free amino acid content of faecal samples

Collected samples were homogenised in $400 \mu \mathrm{l}$ of $40 \mathrm{mM}$ Tris buffer containing SigmaFast ${ }^{\mathrm{TM}}$
Protease inhibitor tablets, followed by centrifugation at $14000 \times g$ for $10 \mathrm{~min}$. The supernatant was diluted 50 times before determining the total soluble protein content by the Bradford assay, using Sigma Bradford Reagent (Sigma-Aldrich, 
St Louis, MO, USA) according to the manufacturer's instructions with BSA as standard (SigmaAldrich, St Louis, MO, USA). Absorbance was measured at $595 \mathrm{~nm}$ using a BioTek Eon microplate reader (Analytical and Diagnostic Products, Johannesburg, South Africa).

Uric acid in each sample was determined by an enzyme-based colorimetric assay using a commercial kit (Uric Acid Assay Kit MAK077, SigmaAldrich Co., St. Louis, MO, USA). Three hundred microliters of the provided uric acid assay buffer were added to $100 \mu \mathrm{l}$ of the remaining homogenate. Samples were vortexed vigorously and centrifuged at $14000 \times g$ for $10 \mathrm{~min}$. Twelve microliters of the supernatant were transferred to a 96-well plate (in triplicate) before adding uric acid assay buffer to a final volume of $50 \mu \mathrm{l}$ and performing the assay according to the manufacturer's instructions.

The free amino acid content was determined using a Waters AccQTag ${ }^{\mathrm{TM}}$ Ultra Chemistry kit (Milford, MA, USA) which includes the AccQTag ${ }^{\text {TM }}$ Ultra Derivatization Kit, an AccQTag ${ }^{\text {TM }}$ Ultra $\mathrm{C}_{18}$ column $(2.1 \times 100 \mathrm{~mm} \times$ $1.7 \mu \mathrm{m})$, as well Eluents A and B. Before derivatization, the freeze-dried samples were reconstituted in $500 \mu \mathrm{l}$ double-distilled deionised water (using vortexing and ultrasonication) before precipitating the proteins by adding $500 \mu \mathrm{l}$ of acetonitrile. After centrifugation, $800 \mu \mathrm{l}$ of the supernatant was concentrated by complete evaporation followed by reconstitution in $200 \mu \mathrm{l}$ Eluent A before adding the internal standard L-norvaline to a final concentration of $20 \mathrm{ppm}$. The chromatographic analysis was performed on an ACQUITY UPLC $^{\text {TM }}$ system coupled to a Waters PDA detector (Milford, MA, USA) with MassLynx ${ }^{\mathrm{TM}}$ software. Column temperature was maintained at 60 ${ }^{\circ} \mathrm{C}$ and the flow rate was $0.7 \mathrm{ml} / \mathrm{min}$. The following gradient was used: $0-0.54 \mathrm{~min}, 0.1 \% \mathrm{~B} ; 0.54$ $5.74 \mathrm{~min}, 0.1-9.1 \% \mathrm{~B} ; 5.74-7.74 \mathrm{~min}, 9.1-21.2 \%$ B; 7.74-8.04 min, 21.2-59.6\% B; 8.04-8.05 min, $59.6-90.0 \% \mathrm{~B} ; 8.05-8.64 \mathrm{~min}, 90.0 \% \mathrm{~B} ; 8.64$ $8.73 \mathrm{~min}, 90.0-0.1 \% \mathrm{~B}$; and $8.73-9.50 \mathrm{~min}, 0.1 \%$ B. The injection volume was $1 \mu \mathrm{l}$.

\subsection{Statistical analysis}

All data were evaluated for normality and homogeneity of variance prior to analysis. Kaplan-
Meier survival regression analyses were performed to test for differences in survival between test diets, followed by Kruskal-Wallis ANOVA with multiple comparisons of mean ranks. ANOVA and post hoc comparisons were performed to evaluate the effect of the different test diets on consumption, protein digestive efficiency, uric acid excretion and free amino acid content in the rectum. When the data distribution was normal but the assumption of homogeneity of variance was violated, Welch ANOVA was used. The alpha level was set to 0.05 for all analyses. All analyses were performed using IBM SPSS® Statistics v25.

\section{RESULTS}

\subsection{Effect of dietary protein content and oxytetracycline on survival}

Cumulative survival was not significantly affected by protein content or the presence or absence of oxytetracycline when the bees consumed test diets for 3,6 , or 9 days $[\mathrm{H}(7)=2.750, \mathrm{p}=$ $0.907 ; \mathrm{H}(7)=2.865, \mathrm{p}=0.897 ; \mathrm{H}(7)=1.276, \mathrm{p}=$ $0.287]$, compared to sugar-only diet controls (Figure 1B). Survival during the feeding trials was high at day 3, ranging between 97 and $100 \%$ and decreased slowly to $83-91 \%$ at day 6 . After day 6, survival decreased more rapidly and ranged from 43 to $53 \%$ at day 9 . At day 12 , the average survival decreased to $<30 \%$. Consequently, bees fed the test diets for 9 days and then sampled on day 12 were excluded from protein digestive efficiency calculations, as the number of bees remaining in these cages was too low to allow random and representative sampling from a cage.

\subsection{Effect of dietary protein concentration on diet consumption, protein intake and excretion of protein, uric acid and free amino acids}

Cumulative diet consumption did not differ significantly between protein diets consumed for 3 , 6, or 9 days (Figure 2A). When the average daily diet consumption per bee (Figure S2) was compared across protein diets fed for 3, 6 and 9 days, there was a significant difference for the 

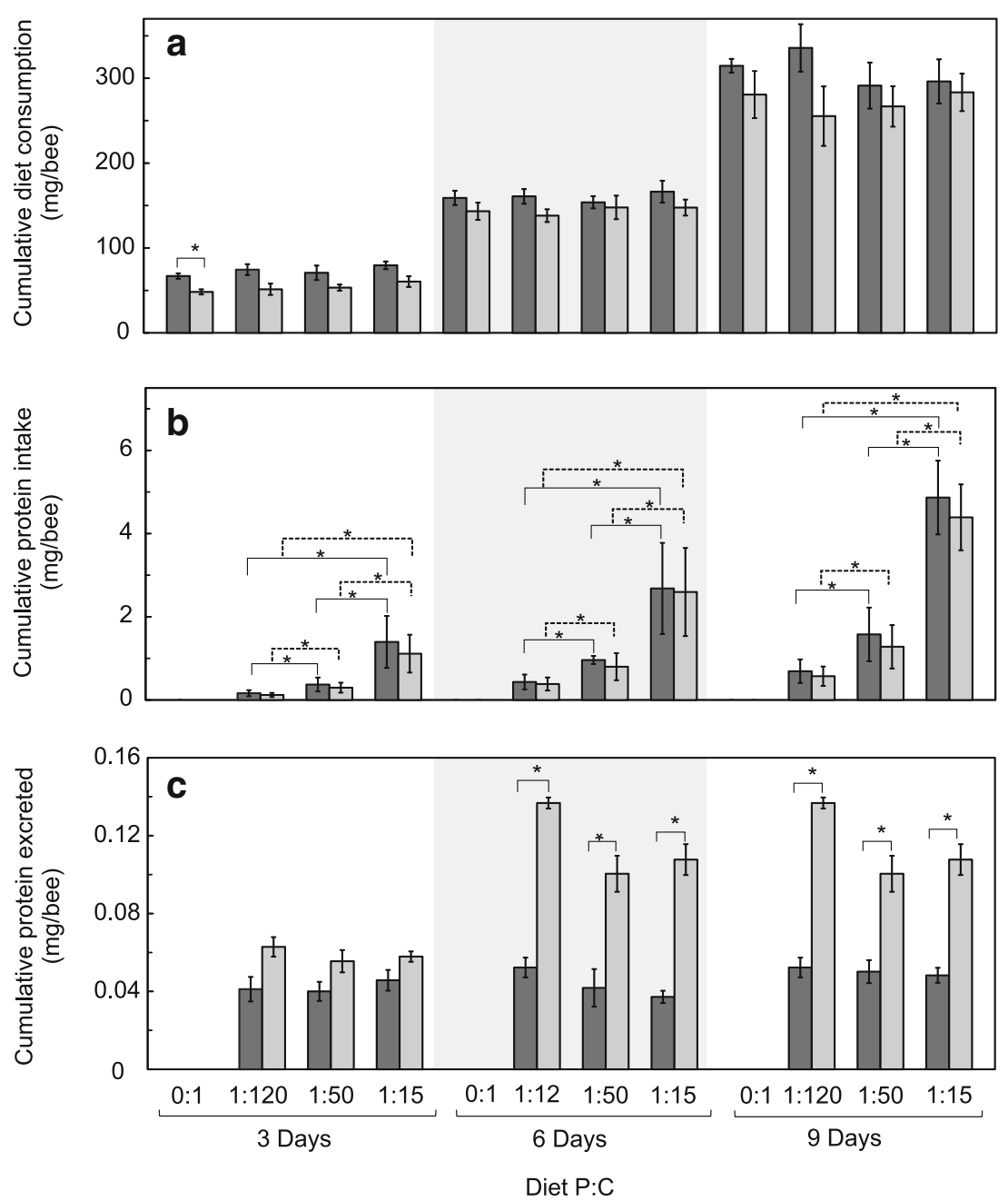

Figure 2. Cumulative diet consumption, protein intake and protein excretion. Indicated is the total diet consumed $[\mathbf{A}]$, along with the cumulative protein intake $[\mathbf{B}]$ and excretion $[\mathbf{C}]$ across varying levels of dietary protein in the presence and absence of $450 \mu \mathrm{g} / \mathrm{ml}$ oxytetracycline (OTC) in bees fed for 3, 6 and 9 days. Data are presented as the mean $\pm \mathrm{SE}(\mathrm{N}=6 ; 50$ bees per cage). Significant differences are indicated with an asterisk $(*)$ (Welch ANOVA, $\mathrm{p}<$ $0.05)$. Samples obtained from the control diets ( $0: 1$, sucrose-only) were used to correct for endogenous protein in the rectum.

sucrose-only (P:C 0:1) control diets [Welch $F$ (11, $18.268)=8.608, \mathrm{p}<0.001]$, but not for the protein diets. Bees consuming the sucrose-only diet without oxytetracycline for 9 days consumed slightly more per day than bees subsisting on sucrose diets for 3 [mean difference $12.655 \mathrm{mg} / \mathrm{bee} \mathrm{p}=0.001$ ] or 6 [mean difference $8.474 \mathrm{mg} / \mathrm{bee}, \mathrm{p}=0.049$ ] days (Figure S2). Taken together, these analyses suggest that dietary protein content does not significantly influence food intake.
Because total diet consumption did not differ between diets, protein intake was significantly higher for cohorts of bees on the higher protein $\operatorname{diet}(\mathrm{P}: \mathrm{C} 1: 15$ and 1:50) compared to those on the low-protein diet (P:C 1:120) over 3 [Welch $F$ (5, $11.808)=62.106, \mathrm{p}<0.001], 6[$ Welch $F(1$, $13.576)=0.743, \mathrm{p}<0.001]$, or $9[$ Welch $F(5$, $13.166)=34.038, \mathrm{p}<0.001]$ days (Figure 2B). Specifically, protein intake on $\mathrm{P}: \mathrm{C}$ 1:15 diets was greater than P:C 1:50 diets $(\mathrm{p}<0.001, \mathrm{p}<0.001, \mathrm{p}$ 
Table I. Total uric acid and free amino acids detected in excreta of bees fed on varying protein diets. Data presented as the mean $\pm \mathrm{SE}(\mathrm{N}=6 ; 50$ bees per cage)

\begin{tabular}{|c|c|c|c|c|}
\hline Days & Diet(s) P:C & $\begin{array}{l}\text { Uric acid } \\
(\mu \mathrm{g} / \mathrm{bee}) \\
\text { Mean } \pm \mathrm{SE}^{*}\end{array}$ & $\begin{array}{l}\% \text { Uric acid in total excreta } \\
\text { Mean } \pm \mathrm{SE}^{*}\end{array}$ & $\begin{array}{l}\text { Total free amino acids }(\mu \mathrm{g} / \mathrm{bee}) \\
\text { Mean } \pm \mathrm{SE}^{*}\end{array}$ \\
\hline \multirow[t]{4}{*}{3} & $0: 1$ & $21.49 \pm 2.31$ & $1.35 \pm 0.14$ & $6.63 \pm 1.05$ \\
\hline & $1: 15$ & $17.77 \pm 2.39$ & $1.17 \pm 0.15$ & $11.15 \pm 0.81$ \\
\hline & $1: 50$ & $16.42 \pm 3.34$ & $1.29 \pm 0.26$ & $10.85 \pm 1.84$ \\
\hline & $1: 120$ & $16.42 \pm 1.86$ & $1.13 \pm 0.12$ & $7.42 \pm 1.38$ \\
\hline \multirow[t]{4}{*}{6} & $0: 1$ & $20.99 \pm 2.88$ & $1.23 \pm 0.16$ & $8.34 \pm 0.99$ \\
\hline & $1: 15$ & $15.89 \pm 1.54$ & $1.20 \pm 0.11$ & $9.76 \pm 2.27$ \\
\hline & $1: 50$ & $17.27 \pm 2.45$ & $1.07 \pm 0.15$ & $9.07 \pm 2.01$ \\
\hline & $1: 120$ & $16.21 \pm 3.15$ & $0.9 \pm 0.17$ & $6.34 \pm 0.58$ \\
\hline
\end{tabular}

*No significant differences detected (Welch ANOVA, $\mathrm{p}<0.05$ )

${ }^{\mathrm{a}} \mathrm{g} / 100 \mathrm{~g}$ dried excreta
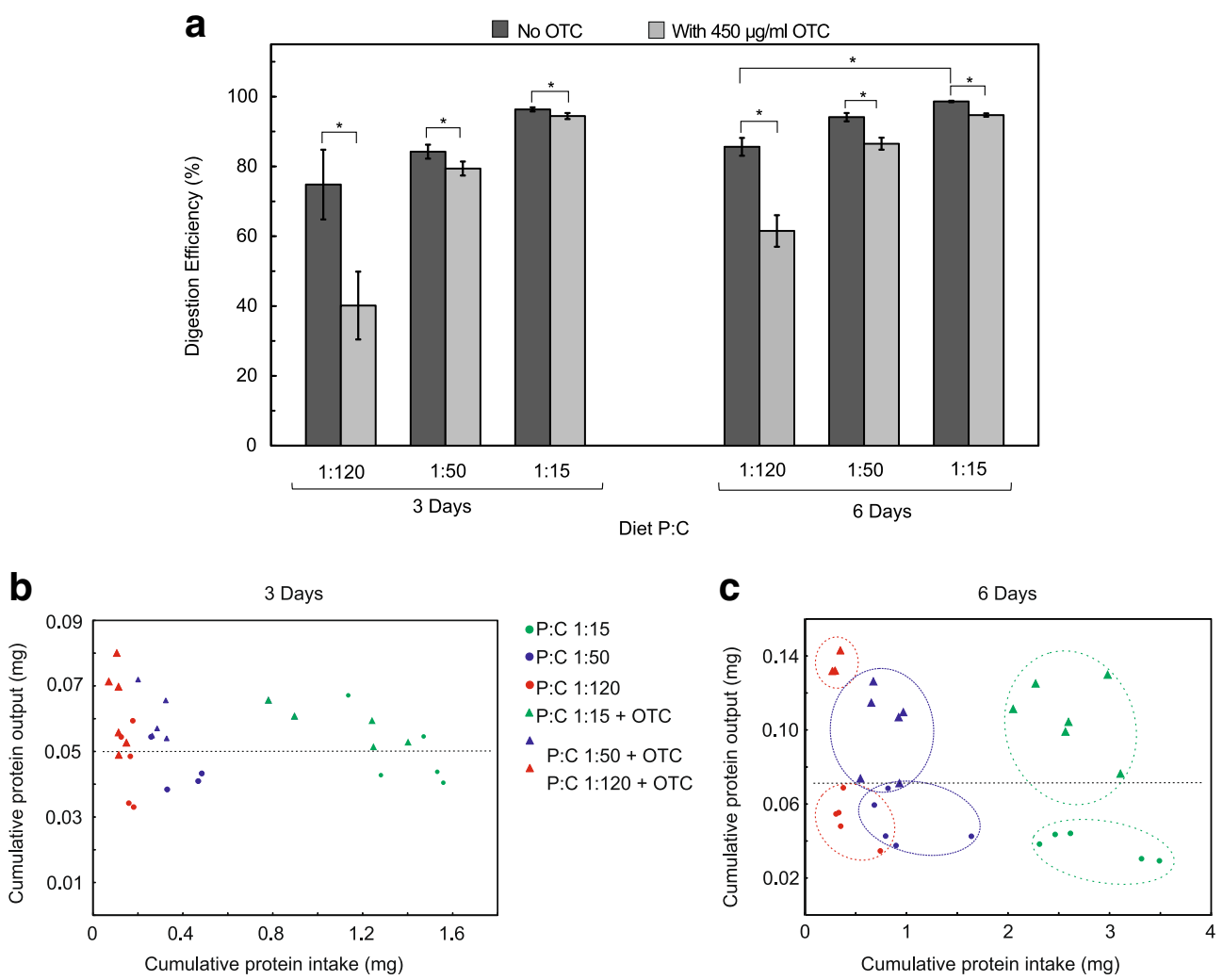

Figure 3. Protein digestion efficiency and the protein utilisation plots in the presence and absence of oxytetracycline. [A] Protein digestion efficiency in the presence and absence of the antibiotic OTC. Scatter plots show protein intake relative to protein output following $3[\mathbf{B}]$ and $6[\mathbf{C}]$ days of feeding on various protein to carbohydrate (P:C) diets with or without OTC. Data is presented as the mean $\pm \mathrm{SE}(\mathrm{N}=6,50$ bees per cage). Significant differences are indicated with an asterisk $(*)$ (Welch ANOVA, $\mathrm{p}<0.05$ ). 
$=0.014$ for 3,6 and 9 days, respectively) and $\mathrm{P}: \mathrm{C}$ $1: 120$ diets $(p=0.001, p<0.001, p=0.005$ for 3 , 6 and 9 days, respectively). Protein intake for $P: C$ 1:50 was also greater than protein intake for $\mathrm{P}: \mathrm{C}$ $1: 120(p=0.048, p<0.001, p<0.001$ for 3,6 and 9 days, respectively). However, a higher protein intake did not generate any significant difference in uric acid [Welch $F(11,20.179)=0.632, \mathrm{p}=$ 0.782 ], total free amino acid content [Welch $F$ (7, $5.993)=1.475, \mathrm{p}=0.146]$ (Table I, Table SI), or cumulative undigested protein [Welch $F$ (17, $16.919)=0.980]$ (Figure $2 \mathrm{C}$ and Table SII) in the excreta.

Protein digestive efficiency was significantly affected by protein intake [Welch $F(8,13.325)$ $=27.243, \mathrm{p}<0.001]$, increasing with higher protein intake as illustrated in Figure 3A. For 3-dayold bees, the increase in digestive efficiency with increased levels of dietary protein was not significant. However, when 6-day-old bees consumed the high-protein diet (P:C 1:15), protein digestive efficiency was significantly higher than on the low-protein diet (P:C 1:120) [p = 0.039].

\subsection{Effect of dietary oxytetracycline on diet consumption, protein intake and protein excretion}

Bees consuming sucrose-only diets (P:C 0:1) for 3 days consumed significantly less when oxytetracycline was present in the diets $(\mathrm{p}=0.043)$ (Figure 2A). For all other diets, there were no significant differences in cumulative diet consumption (Figure 2A) or daily average consumption per bee (Figure S2) in the presence or absence of oxytetracycline. Consequently, oxytetracycline had no effect on protein intake overall (Figure 2B). When we compared cumulative protein intake and output for 3 and 6 days (Figure 3B and $\mathrm{C}$, respectively), with or without oxytetracycline in the diet, a pronounced shift along the vertical axis for cumulative protein output was only observed after 6 days on diets containing oxytetracycline. The presence of dietary oxytetracycline significantly increased protein excretion [Welch $F(17,27.240)=37.736, \mathrm{p}<0.001]$ when protein diets containing oxytetracycline were consumed over 6 days [P:C 1:15 < P:C 1:15 + oxytetracycline, $\mathrm{p}=0.004 ; \mathrm{P}: \mathrm{C} 1: 50<\mathrm{P}: \mathrm{C} 1: 50+$ oxytetracycline, $\mathrm{p}=0.059$ and $\mathrm{P}: \mathrm{C} 1: 120<\mathrm{P}: \mathrm{C}$ $1: 120+$ oxytetracycline, $\mathrm{p}<0.001]$ (Figure 2C). A significant decrease in protein digestive efficiency was observed in the presence of dietary oxytetracycline when consumed for 3 [Welch $F$ $(5,10.712)=17.199, \mathrm{p}<0.001]$ and 6 [Welch $F$ $(5,11.237)=22.41, \mathrm{p}<0.001]$ days. Specifically, protein digestion efficiency decreased significantly in the presence of oxytetracycline when bees consumed low (P:C 1:120, $\mathrm{p}=0.005 ; \mathrm{p}=0.017$ ) and intermediate $(\mathrm{P}: \mathrm{C} 1: 50, \mathrm{p}=0.034 ; \mathrm{p}=0.049)$ protein diets for 3 and 6 days. The most pronounced decreases in digestion efficiency were observed when bees were fed the low-protein diets (Figure 3A).

\section{DISCUSSION}

Here we show that protein digestive efficiency of honeybees, contrary to expectation, increases with increasing levels of protein in the diet. Importantly, we show that antibiotic exposure impairs protein digestive efficiency, with the negative affect becoming more pronounced during consumption of low-protein diets.

The varying protein levels in the test diets had no adverse impact on survival. For the African honeybee, Apis mellifera scutellata, the survival curves are not out of the ordinary and within the range of what we have recorded in previous studies using caged Apis mellifera scutellata (Démares et al. 2016; Archer et al. 2014a, 2014b; Köhler et al. 2012; Altaye et al. 2010; Pirk et al. 2010). Although we have previously shown that overconsumption of protein shortens the life span of honeybees (Archer et al. 2014a; Paoli et al. 2014; Altaye et al. 2010; Pirk et al. 2010), this effect may be more pronounced in longer-term survival studies or when feeding on diets with higher protein concentrations. Likewise, we found no effect of oxytetracycline on survival, in contrast with Raymann et al. (2017) which reported decreased survival after treating bees with tetracycline for 5 days followed by exposure to bacterial pathogens for 10 days. $\mathrm{Li}$ et al. (2019) measured significant decreases in survival of bees treated with a mixture of penicillin and streptomycin for 15 days, partially counteracted by including pollen in the diet. 
By monitoring food consumption, we can surmise to what extent the bees regulated their nutrient intake. The varying levels of dietary protein had no impact on diet consumption, suggesting that the bees regulated their carbohydrate intake rather than protein intake. This strong bias of broodless workers towards dietary carbohydrate was also demonstrated in our previous studies that investigated nutrient intake in honeybees, with intake targets converging on low protein to carbohydrate ratios when feeding on artificial (Archer et al. 2014a; Démares et al. 2016) or natural diets (Altaye et al. 2010; Pirk et al. 2010; Human et al. 2007). The nutrient intake of caged worker bees without the demands of larvae to feed is more closely related to their own physiological requirements than those of a colony (Lass and Crailsheim 1996). The propensity to keep carbohydrate intake high and constant may reflect the high metabolic rate of honeybees even under resting conditions (Kovac et al. 2007). Honeybees also keep their blood glucose levels rather constant and digest nearly all the carbohydrate they consume (Crailsheim 1988). As in previous studies (Archer et al. 2014a; Köhler et al. 2012), older 9-day-old bees consumed slightly more per day of the sucrose-only diet (P:C 0:1) than 3- and 6-dayold bees. This is consistent with the transition from hive worker to forager and the accompanying physiological changes (Crailsheim et al. 1992). Interestingly, in several of the cages that were fed protein diets for more than 3 days, bees were observed to have active wax glands which enabled them to build small combs on the wax foundation. This indicates that minimum nutritional requirements to allow normal gland development were met.

The presence of oxytetracycline also had no significant effect on diet consumption. Only bees consuming a sucrose-only diet for the first 3 days after emergence consumed significantly less when oxytetracycline was present in the diet, indicating that they might be able to taste the oxytetracycline. Evidently, bees do not experience any perceptible malaise effects after consumption of oxytetracycline, which would have induced lower diet intake.

Since total diet consumption did not differ between protein-containing diets, protein intake increased with the proportion of protein in the diet (Figure 2). Because protein excretion levels did not reflect a similar trend, the digestive efficiency of protein increased with dietary protein content (Figure 3). This was more pronounced in 6-dayold bees, consistent with the age-related increase of proteolytic activity in nurse bees (Crailsheim and Stolberg 1989). Limited research suggesting that protein intake influences protein digestive efficiency in bees (DeGrandi-Hoffman et al. 2016; Brodschneider and Crailsheim 2010), together with the evidence that caged workers can regulate protein intake to maintain low protein to carbohydrate ratios (Démares et al. 2016; Archer et al. 2014a; Altaye et al. 2010), led to our expectation that protein digestive efficiency would decrease on the high-protein no-choice test diets to maintain the balance of nutrients absorbed postingestively. This would be similar to what is observed in L. migratoria (Clissold et al. 2010). However, the observed increase in protein digestive efficiency with increased levels of protein is in better agreement with the view that animals maximise nutrient absorption from food by modulating levels of digestive enzymes and transporters coupled with post-absorptive mechanisms to regulate retention and eliminate surpluses (Karasov et al. 2011).

It is possible that, as in tobacco budworms (Heliothis virescens) (Telang et al. 2003), excess protein is digested and absorbed across the gut before being eliminated as uric acid (McNally et al. 1965). In honeybees, the nitrogenous waste products of protein catabolism are mainly excreted as uric acid, with very small percentages of amino nitrogen, creatine and creatinine (McNally et al. 1965). Although the levels of uric acid excretion varied to some extent across the test diets, these changes were not significant (Table I). The mean levels of $1.2 \%$ in the total excreta can be compared to the $2.2 \%$ uric acid detected in the excreta of bees fed casein by McNally et al. (1965). There were also no significant changes in excretion of free amino acids, another possible route of eliminating excess protein (McNally et al. 1965) (Table I and Table SI; rectal amino acid content of the oxytetracyclinetreated groups was not determined). Amino acids in the rectal contents were determined and 
compared between age groups but did not include other regions of the gut where the bee microbiota may contribute to the total amino acid pool as demonstrated by Kešnerová et al. (2017) and Zheng et al. (2017) who used whole guts and specific regions of the gut, respectively. A difference in amino acid content in the rectum would be expected if amino acids are present in excess in bees fed high-protein diets, which does not seem to be the case. It is possible that the excess protein is catabolised, absorbed across the gut epithelium and contributes to jelly production in the hypopharyngeal glands (Crailsheim et al. 1992). Measurement of the total protein content of the heads of the bees would confirm increased jelly production and storage. However, Altaye et al. (2010) did not find a positive correlation between dietary protein levels and hypopharyngeal gland activation within a specific age group. It is more likely that the surplus protein is stored in the haemolymph and fat body as vitellogenin (Cabbri et al. 2018; Amdam and Omholt 2002) and hexamerin 70a (Cabbri et al. 2018; Martins et al. 2008; Amdam and Omholt 2002), the only hexamerin present in adult workers (Danty et al. 1998). It has even been suggested that non-laying workers can store protein in their ovaries as vitellogenin (Amdam and Omholt 2002).

We did not observe any acute effects on survival when cohorts of caged bees were exposed to oxytetracycline. However, the presence of oxytetracycline in the diet reduced protein digestive efficiency, leading to increased levels of undigested protein being excreted by the bees (Figure 2 and Figure 3). Since Raymann et al. (2017) and Li et al. (2019) demonstrated that antibiotics significantly reduce the gut microbiota of honeybees, this result strongly suggests that the gut microbiota play a role in protein digestion as proposed by previous genomic studies (Kakumanu et al. 2016; Lee et al. 2015). The impairment of digestive efficiency was more pronounced when the bees were fed low-protein diets, and Li et al. (2019) similarly found an influence of nutritional stress, with some effects of dietary antibiotics being more dramatic in the absence of pollen.

One of the three major bacterial classes found in the honeybee gut, the Bacilli, has a diverse inventory of proteolytic enzymes (Lee et al.
2015), and these bacteria are the most likely candidates contributing to protein catabolism in bees. Interestingly, the three most dominant clades (Gilliamella, Lactobacillus Firm-5 and Bifidobacterium) can digest pectin (Lee et al. 2015, 2018), a major component of the inner wall layer (intine) that surrounds the protoplasm of pollen grains. In addition, honeybee gut microbiota can utilise other indigestible components of the pollen wall such as $\omega$-hydroxy acids, phenolamides and flavonoid glycosides (Kešnerová et al. 2017). This suggests that the effect of antibiotic exposure on protein metabolism overall may be more substantial when bees consume their natural diet of pollen: the gut microbiota might not only be involved in protein catabolism but might also make the protein more accessible by digesting the pectin component of the pollen wall as well as other hard to digest components of the pollen wall.

The effect of oxytetracycline on digestive efficiency is more prominent when the bees consume the low-protein diet. At lower protein levels, the host may rely more on the microbiota for the digestion capacity than on its own enzymes: only when the protein levels are higher does the host increase the capacity to digest protein by secreting more proteolytic enzymes, as it is metabolically expensive to maintain high levels of digestive enzymes (Karasov and Douglas 2013). There is evidence that an insect host and its gut microbes can contribute distinct but complementary enzymes to the same metabolic pathway (Douglas 2009).

Honey bees acquire the full complement of the gut microbiome mainly through contact with hive members after eclosion (Powell et al. 2014). Workers were collected from the brood frame within $24 \mathrm{~h}$ of emergence and likely did not acquire the full microbiome complement, nor were these bees artificially supplemented with their natural microbiome. For the purpose of investigating whether antibiotic treatment affects protein digestive efficiency, both the control and the experimental groups were treated consistently in regard to acquisition of the gut microbiome. It would be interesting to perform similar experiments with bees with a confirmed full gut microbiome complement as the effect of oxytetracycline on protein digestive 
efficiency might have been underestimated in our experiments.

Although antibiotic exposure has no immediate acute effects, overexposure to antibiotics likely leads to downstream effects very similar to those when there is no adequate source of protein available to honeybees. The impact on protein digestive efficiency is more pronounced when consuming a low-protein diet, which has implications for honeybee management practices. When colonies are restricted to a single protein deficient source of pollen, such as when pollinating a monoculture of sunflowers (Nicolson and Human 2013), antibiotic exposure could exacerbate the negative effects of the low-protein diet. Collectively, this knowledge broadens our understanding of the factors that influence the digestive efficiency protein in honeybees, which in turn aids in developing effective strategies to reduce the risks of developing protein deficiencies in managed colonies of honeybees.

\section{ACKNOWLEDGEMENTS}

We thank G. Wright and Z. Apostolides for useful discussions.

\section{AUTHORS' CONTRIBUTIONS}

S.W.N conceived the study. All authors designed the study. E.E.dR, C.S. and H.H. performed the experiments. E.E.dR performed data analysis and wrote the first draft of the manuscript. C.W.W.P. and S.W.N. contributed to revisions and secured funding. All authors gave final approval for publication.

\section{FUNDING INFORMATION}

This work was supported by the University of Pretoria, including a postdoctoral scholarship to E.E.dR, and by the National Research Foundation of South Africa to S.W.N. and C.W.W.P.

Un traitement antibiotique entrave la digestion des protéines chez Apis mellifera.

nutrition des abeilles / digestion des protéines / antibiotique / oxytétracycline.
Eine Antibiotikabehandlung beeinträchtigt die Eiweißverdauung bei der Honigbiene Apis mellifera .

\section{Bienenernährung / Eiweißverdauung / Antibiotika / Oxytetracycline.}

\section{REFERENCES}

Alaux, C., Ducloz, F., Crauser, D., and Le Conte, Y. (2010). Diet effects on honeybee immunocompetence. Biol. Lett. 6 (4), 562-565.

Altaye, S.Z., Pirk, C.W.W., Crewe, R.M., and Nicolson, S.W. (2010). Convergence of carbohydrate-biased intake targets in caged worker honeybees fed different protein sources. J. Exp. Biol. 213 (19), 3311-3318.

Amdam, G.V. and Omholt, S.W. (2002). The regulatory anatomy of honeybee lifespan. J. Theor. Biol. 216 (2), 209-228.

Archer, C.R., Pirk, C.W.W., Wright, G.A., and Nicolson, S.W. (2014a). Nutrition affects survival in African honeybees exposed to interacting stressors. Funct. Ecol. 28 (4), 913-923.

Archer, C.R., Köhler, A., Pirk, C.W.W., Oosthuizen, V., Apostolides, Z., and Nicolson, S.W. (2014b). Antioxidant supplementation can reduce the survival costs of excess amino acid intake in honeybees. J. Insect Physiol. 71, 78-86.

Avni, D., Hendriksma, H.P., Dag, A., Uni, Z., and Shafir, S. (2014). Nutritional aspects of honey bee-collected pollen and constraints on colony development in the eastern Mediterranean. J. Insect Physiol. 69, 65-73.

Behmer, S.T. (2009). Insect herbivore nutrient regulation. Annu. Rev. Entomol. 54, 165-187.

Brodschneider, R. and Crailsheim, K. (2010). Nutrition and health in honey bees. Apidologie 41 (3), 278-294.

Cabbri, R., Ferlizza, E., Nanetti, A., Monari, E., Andreani, G., Galuppi, R., and Isani, G. (2018). Biomarkers of nutritional status in honeybee haemolymph: effects of different biotechnical approaches for Varroa destructor treatment and wintering phase. Apidologie 49 (5), 606-618.

Chopra, I. and Roberts, M. (2001). Tetracycline antibiotics: mode of action, applications, molecular biology, and epidemiology of bacterial resistance. Microbiol. Mol. Biol. Rev. 65 (2), 232-260.

Clissold, F.J., Tedder, B.J., Conigrave, A.D., and Simpson, S.J. (2010). The gastrointestinal tract as a nutrientbalancing organ. Proc. R. Soc. B Biol. Sci. 277 (1688), 1751-1759.

Clissold, F.J., Brown, Z.P., and Simpson, S.J. (2013). Protein-induced mass increase of the gastrointestinal tract of locusts improves net nutrient uptake via larger meals rather than more efficient nutrient absorption. J. Exp. Biol. 216 (2), 329-337.

Crailsheim, K. (1988). Regulation of food passage in the intestine of the honeybee (Apis mellifera L.). J. Insect Physiol. 34 (2), 85-90. 
Crailsheim, K. and Stolberg, E. (1989).Influence of diet, age and colony condition upon intestinal proteolytic activity and size of the hypopharyngeal glands in the honeybee (Apis mellifera L.). J Insect Physiol. 35 (8), 595-602.

Crailsheim, K., Schneider, L.H.W., Hrassnigg, N., Bühlmann, G., Brosch, U., Gmeinbauer, R., and Schöffmann, B. (1992). Pollen consumption and utilization in worker honeybees (Apis mellifera carnica): dependence on individual age and function. J. Insect Physiol. 38 (6), 409-419.

Danty, E., Arnold, G., Burmester, T., Huet, J.-C., Huet, D., Pernollet, J.-C., and Masson, C. (1998). Identification and developmental profiles of hexamerins in antenna and hemolymph of the honeybee, Apis mellifera. Insect Biochem. Mol. Biol. 28 (5-6), 387-397.

Davila, A., Blachier, F., Gotteland, M., Andriamihaja, M., Benetti, P.-H., Sanz, Y., and Tomé, D. (2013). Intestinal luminal nitrogen metabolism: role of the gut microbiota and consequences for the host. Pharmacol. Res. 68 (1), 95-107.

DeGrandi-Hoffman, G., Chen, Y., Rivera, R., Carroll, M., Chambers, M., Hidalgo, G., and de Jong, E.W. (2016). Honey bee colonies provided with natural forage have lower pathogen loads and higher overwinter survival than those fed protein supplements. Apidologie 47 (2), 186-196.

Démares, F.J., Crous, K.L., Pirk, C.W.W., Nicolson, S.W., and Human, H. (2016). Sucrose sensitivity of honey bees is differently affected by dietary protein and a neonicotinoid pesticide. PLOS ONE 11 (6), e0156584.

Di Pasquale, G., Alaux, C., Le Conte, Y., Odoux, J.-F., Pioz, M., Vaissiere, B.E., Belzunces, L.P., and Decourtye, A. (2016). Variations in the availability of pollen resources affect honey bee health. PLOS ONE 11 (9), e0162818.

Douglas, A.E. (2009). The microbial dimension in insect nutritional ecology. Funct. Ecol. 23 (1), 38-47.

Genersch, E. (2010). American Foulbrood in honeybees and its causative agent, Paenibacillus larvae. J. Invertebr. Pathol. 103, S10-S19.

Goulson, D., Nicholls, E., Botias, C., and Rotheray, E.L. (2015). Bee declines driven by combined stress from parasites, pesticides, and lack of flowers. Science $\mathbf{3 4 7}$ (6229), 1255957-1255957.

Human, H., Nicolson, S.W., Strauss, K., Pirk, C.W.W., and Dietemann, V. (2007). Influence of pollen quality on ovarian development in honeybee workers (Apis mellifera scutellata). J. Insect Physiol. 53 (7), 649655.

Kakumanu, M.L., Reeves, A.M., Anderson, T.D., Rodrigues, R.R., and Williams, M.A. (2016). Honey bee gut microbiome is altered by in-hive pesticide exposures. Front. Microbiol. 7, 1255.

Karasov, W.H. and Douglas, A.E. (2013). Comparative digestive physiology. Compr. Physiol. 3 (2), 741-783.

Karasov, W.H., Martínez del Rio, C., and Caviedes-Vidal, E. (2011). Ecological physiology of diet and digestive systems. Annu. Rev. Physiol. 73 (1), 69-93.
Kešnerová, L., Mars, R.A.T., Ellegaard, K.M., Troilo, M., Sauer, U., and Engel, P. (2017). Disentangling metabolic functions of bacteria in the honey bee gut. PLOS Biol. 15 (12), e2003467.

Koch, H. and Schmid-Hempel, P. (2011). Socially transmitted gut microbiota protect bumble bees against an intestinal parasite. Proc. Natl. Acad. Sci. 108 (48), 19288-19292.

Köhler, A., Pirk, C.W.W., and Nicolson, S.W. (2012). Honeybees and nectar nicotine: deterrence and reduced survival versus potential health benefits. J. Insect Physiol. 58 (2), 286-292.

Kovac, H., Stabentheiner, A., Hetz, S.K., Petz, M., and Crailsheim, K. (2007). Respiration of resting honeybees. J. Insect Physiol. 53 (12), 1250-1261.

Kwong, W.K. and Moran, N.A. (2016). Gut microbial communities of social bees. Nat. Rev. Microbiol. 14 (6), 374-384.

Lass, A. and Crailsheim, K. (1996). Influence of age and caging upon protein metabolism, hypopharyngeal glands and trophallactic behavior in the honey bee (Apis mellifera L.). Insectes Sociaux 43 (4), 347-358.

Lee, F.J., Rusch, D.B., Stewart, F.J., Mattila, H.R., and Newton, I.L.G. (2015). Saccharide breakdown and fermentation by the honey bee gut microbiome: fermentation by honey bee gut microbes. Environ. Microbiol. 17 (3), 796-815.

Lee, F.J., Miller, K.I., McKinlay, J.B., and Newton, I.L.G. (2018). Differential carbohydrate utilization and organic acid production by honey bee symbionts. FEMS Microbiol. Ecol. 94 (8), 1-10.

Li, J., Heerman, M.C., Evans, J.D., Rose, R., Li, W., Rodríguez-García, C., DeGrandi-Hoffman, G., Zhao, Y., Huang, S., Li, Z., Hamilton, M., and Chen, Y. (2019). Pollen reverses decreased lifespan, altered nutritional metabolism and suppressed immunity in honey bees (Apis mellifera) treated with antibiotics. J. Exp. Biol. 222 (7), jeb202077.

Martins, J.R., Morais Franco Nunes, F., Luz Paulino Simões, Z., and Maria Gentile Bitondi, M. (2008). A honeybee storage protein gene, hex $70 \mathrm{a}$, expressed in developing gonads and nutritionally regulated in adult fat body. J. Insect Physiol. 54 (5), 867-877.

McNally, J.B., McCaughey, W.F., Standifer, L.N., and Todd, F.E. (1965). Partition of excreted nitrogen from honey bees fed various proteins. J. Nutr. 85 (1), 113116.

Moran, N.A., Hansen, A.K., Powell, J.E., and Sabree, Z.L. (2012). Distinctive gut microbiota of honey bees assessed using deep sampling from individual worker bees. PLoS ONE 7 (4), e36393.

Nicolson, S.W. and Human, H. (2013). Chemical composition of the 'low quality' pollen of sunflower (Helianthus annuus, Asteraceae). Apidologie 44 (2), 144-152.

Nicolson, S.W., Da Silva Das Neves, S., Human, H., and Pirk, C.W.W. (2018). Digestibility and nutritional value of fresh and stored pollen for honey bees (Apis mellifera scutellata ). J. Insect Physiol. 107, 302-308. 
Paoli, P.P., Donley, D., Stabler, D., Saseendranath, A., Nicolson, S.W., Simpson, S.J., and Wright, G.A. (2014). Nutritional balance of essential amino acids and carbohydrates of the adult worker honeybee depends on age. Amino Acids 46 (6), 1449-1458.

Pirk, C.W.W., Boodhoo, C., Human, H., and Nicolson, S.W. (2010). The importance of protein type and protein to carbohydrate ratio for survival and ovarian activation of caged honeybees (Apis mellifera scutellata). Apidologie 41 (1), 62-72.

Powell, J.E., Martinson, V.G., Urban-Mead, K., and Moran, N.A. (2014) Routes of acquisition of the gut microbiota of the honey bee Apis mellifera. Appl. Environ. Microbiol. 80 (23), 7378-7387.

Raymann, K., Shaffer, Z., and Moran, N.A. (2017). Antibiotic exposure perturbs the gut microbiota and elevates mortality in honeybees. PLoS Biol. 15 (3), e2001861.

Schmehl, D.R., Teal, P.E.A., Frazier, J.L., and Grozinger, C.M. (2014). Genomic analysis of the interaction between pesticide exposure and nutrition in honey bees (Apis mellifera ). J. Insect Physiol. 71, 177-190.

Schmidt, J.O. and Buchmann, S.L. (1985). Pollen digestion and nitrogen utilization by Apis mellifera L. (Hymenoptera: Apidae). Comp. Biochem. Physiol. A Physiol. 82 (3), 499-503.

Scofield, H.N. and Mattila, H.R. (2015). Honey bee workers that are pollen stressed as larvae become poor foragers and waggle dancers as adults. Plos One $\mathbf{1 0}$ (4), e0121731.

Telang, A., Buck, N.A., Chapman, R.F., and Wheeler, D.E. (2003). Sexual differences in postingestive processing of dietary protein and carbohydrate in caterpillars of two species. Physiol. Biochem. Zool. 76 (2), 247-255.

Tian, B., Fadhil, N.H., Powell, J.E., Kwong, W.K., and Moran, N.A. (2012). Long-term exposure to antibiotics has caused accumulation of resistance determinants in the gut microbiota of honeybees. mBio 3 (6), e0037712.

Vanbergen, A.J. and the Insect Pollinators Initiative (2013). Threats to an ecosystem service: pressures on pollinators. Front. Ecol. Environ. 11 (5), 251-259.

Wang, Y., Ma, L., Hang, X., Yang, W., Liu, F., and Xu, B. (2014). Digestion of protein of two pollen types in China by the honeybee (Apis mellifera L.). Apidologie 45 (5), 590-600.

Wright, G.A., Nicolson, S.W., and Shafir, S. (2018). Nutritional physiology and ecology of honey bees. Annu. Rev. Entomol. 63, 327-344.

Yang, Y. and Joern, A. (1994). Gut size changes in relation to variable food quality and body size in grasshoppers. Funct. Ecol. 8 (1), 36-45.

Zanotto, F.P., Simpson, S.J., and Raubenheimer, D. (1993). The regulation of growth by locusts through postingestive compensation for variation in the levels of dietary protein and carbohydrate. Physiol. Entomol. $18,425-434$.

Zheng, H., Nishida, A., Kwong, W.K., Koch, H., Engel, P., Steele, M.I., and Moran, N.A. (2016). Metabolism of toxic sugars by strains of the bee gut symbiont Gilliamella apicola . mBio 7 (6), e01326-16.

Zheng, H., Powell, J.E., Steele, M.I, Dietrich, C., Nishida, A., and Moran, N.A. (2017). Honeybee gut microbiota promotes host weight gain via bacterial metabolism and hormonal signalling. PNAS 114 (18), 4775-4780.

Publisher's note Springer Nature remains neutral with regard to jurisdictional claims in published maps and institutional affiliations. 